\title{
Learning Design Thinking Through a Hands-On Learning Model
}

\author{
Norman Gwangwava, Botswana International University of Science and Technology, Palapye, Botswana
}

\begin{abstract}
Design thinking is a human-centered, team-based, creative, and iterative process for problem-solving. The process focuses on the end-user and applies empathy skills to gain an understanding of the problem. Unlike other design methodologies, design thinking dwells on the most prominent user of the design solution. Industry 4.0 is characterized by fast-changing technology, which requires quick time-to-market solutions. Industry 4.0 applications involve more end-user interaction. In order to design products, applications, and systems that end-users will be comfortable using, designers should engage users throughout the design process. Design thinking brings together key parameters for achieving innovative user-centered design solutions. In addition to bringing together designers to work as multidisciplinary teams, the process factors in a creative environment under which the teams work. The article presents a case study for hands-on learning of design thinking where groups of students were engaged in solving pressing problems encountered by skilled craftsmen in the digital era.
\end{abstract}

\section{KEYWORDS}

Creative Thinking Teaching, Design Methods, Design Thinking, Digital Society, Empathy, Hands-On Learning, Ideation, Industry 4.0, Inquiry-Based Learning, Problem-Based Learning

\section{INTRODUCTION}

Approaches to design of products and systems have evolved over the years. Traditional design approaches have been regarded as "over the fence" methods, referring to their fragmented nature where silos of teams of disjointed departments work on part of the solution and pass on the output to subsequent departments until the final stage of launch. Sequential design methods are generally slow and ineffective. The need to involve the whole design team from the onset bore Concurrent Engineering (CE). CE is a simultaneous process, has team approach, and focuses on the customer. Other techniques such as Quality Function Deployment (QFD), complement concurrent engineering by bringing in customer focus. The history of CE dates back to the 1970s, when Japanese companies started using the method informally. First formal application of the method was by the Defense Advanced Projects Agency (DARPA) in America in 1982 (Menon \& Graham, 1996). CE gained the hype in American, Japanese and European companies for formalizing and simultaneous execution of product-process design activities for new products. Although the customer centricity and multidisciplinary team approach in CE brings innovation, the method is largely a formalized approach to traditional engineering of new products and enhancement of research and development (R\&D) in companies. Among great achievements of $\mathrm{CE}$, are shortening of time-to-market, convergence of diverse 
ideas through multi-disciplinary teams, customer focus, iterative simulation and rapid prototyping, and fewer Engineering Change Orders (ECO) issued after product launch.

The modern economy has transited to an "as a service economy". The $4^{\text {th }}$ industrial revolution (Industry 4.0) is taking place in the digital and knowledge based economy. Simply put, Industry 4.0 is the transition from traditional means of doing work to smart automation, using modern smart technologies. The major enablers of Industry 4.0 are integrated technologies that include Internet of Things (IoT), Cyber Physical Systems (CPS), and Cloud Computing (CC) (Baena, Guarin, Mora, Sauza, \& Retat, 2017; Posada et al., 2015; Kagermann, Helbig, Hellinger, \& Wahlster, 2013). Cyberphysical systems (CPS) are physical and engineered systems, whose operations are monitored, coordinated, controlled and integrated by a computing and communication core (Rajkumar, Lee, Sha, \& Stankovic, 2010). CPS-enabled smart factories have a network of intelligent objects linking products and assets with information from the internet, as well as capturing context information. Many factors contribute to the progression of manufacturing trends through to the current phase (Industry 4.0) and beyond. Some of them include shorter product life cycles, increasing product variation (mass customization), volatile markets, cost reduction pressures, scarce resources, cleaner production, lack of skilled workforce and aging community (Gwangwava, Mpofu, \& Mhlanga, 2016). Modern technologies involve the use of connected sensors that enable data to be shared and accessed by people and machines across bigger networks in the services and manufacturing industries. These technologies extend the internet into the real world, embracing everyday objects (Mell \& Grance, 2011). Individuals and corporate end users access the cloud through internet and access spans over different enterprises and platforms. Industry 4.0 is sustained by a new kind of worker-a knowledge worker. Industry leaders, managers and workers must possess skill sets to adapt and manage their operations in Industry 4.0. Critical thinking, problem solving, innovation, and communication are some crucial skills required in Industry 4.0. Business, education, and government must be innovative in training and retraining the Industry 4.0 compliant workforce.

The concept of design thinking emerged in the early 1980s, but gained increasing attention in the 2000s (Hassi \& Laakso, 2011). The $21^{\text {st }}$ century brought about a shift from product-process oriented design to business sector and service-oriented design. Design thinking helps people to define and solve unstructured problems, which have no historical references. This is typical of Industry 4.0 problems. Design thinking has five major stages: Empathize, Define (the problem), Ideate, Prototype, and Test. Design thinkers are innovators who design better products, services, processes, strategies, spaces, architecture, among various innovative initiatives. The method empowers anyone to solve complex problems that occur around us - in our companies, our countries, and even our planet. Benefits of design thinking include elimination of organizational silos, hence promoting a culture of collaboration and experimentation, helps broaden the design focus beyond functional needs to designing a user experience with an emotional touch, optimizes resources, and rests at the core of organizational strategy and change management.

Increasing complexity in design-oriented problems require innovative approaches of teaching and learning design methods. The greater part of the introduction looked at the progression of design methods up to the current preferred design thinking approach. The education sector is battling to incorporate design thinking in the regular curriculum (Li, et al, 2019; Melles, Anderson, Barrett, \& Thompson-Whiteside, 2015). Renard (2014) presents a hands-on learning model as a vehicle for developing design thinking capacity in students. A studio-based, hands-on, material focused learning model was examined through case studies and in the context of recent scholarship on the topics of design thinking, design process, and studio culture. Noel and Liub (2017) assert that development of design thinking education interventions at primary school level leads to a paradigm shift in education, developing 21 st century skills and predictors of student success such as a growth mindset.

Subsequent sections of the article focus on the literature around design thinking. Attention is drawn towards steps for executing design thinking, iteration from idea to solution launch, requirements engineering, and agile development systems. In order to bring discussions into context, Industry 4.0 
and associated innovation challenges are also explored. A case study where learning and implementing design thinking was applied is used to illustrate how design thinking can mitigate complex and unstructured Industry 4.0 design challenges.

\section{Design Thinking}

Razzouk and Shute (2012) define design thinking as an analytic and creative process that engages a person in opportunities to experiment, create and prototype models, gather feedback, and redesign. Design thinking is a major skill of the Industry 4.0 era and people who have mastered the skill are called design thinkers. Design thinking has become an integral part of the design and engineering fields as well as business. This is because designing of products and services falls at the core of business competitiveness, hence major global companies have committed themselves to becoming design leaders (Dunne \& Martin, 2006). Design thinking is a grounding framework for multidisciplinary teams that communicate and coordinate in conventional design domain activities as well as in different contexts such as business and computing (Brown, 2008; Lindberg, Gumienny, Jobst, \& Meinel, 2010). When organizations focus on the people they are creating for, better products, services, and internal processes which are revolutionary rather than mere incremental are created.

There are several characteristics that a good design thinker should possess (Chesson, 2017; Owen, 2007):

- Human- and environment-centered: continually consider how the design affects human needs. Also consider environmental interests at a level with human interests as primary constraints for the design process.

- $\quad$ Ability to visualize: work visually (i.e., depiction of ideas).

- Predisposition toward multi-functionality: look at different/multiple solutions to a problem and keep the big picture of the problem in mind while focusing on its specifics.

- Systemic vision: treat problems as system problems with opportunities for systemic solutions involving different procedures and concepts to create a holistic solution.

- Ability to use language as a tool: be able to verbally explain the creative process forcing invention where detail is lacking and expressing relationships not obvious visually.

- Affinity for teamwork: develop interpersonal skills that allow communication across disciplines and working with other people.

- Avoiding the necessity of choice: search competing alternatives before moving to choice making or decision making.

- Fail early, fail often: willing to try and ready to fail.

The design thinker's mindset is highly insight-oriented, typically an out-of-the-box thinker, problem solver, and always focused on the consumer's requirements at the crux of ideation.

\section{Design Thinking Models}

Problem solving in design thinking can be best understood through two pairs of terms, visually presented as two diamonds: the problem and solution space on the one hand, and diverging/converging thinking on the other hand. The first gives fundamental insights on how design problems are perceived and constructed, while the second shows how to learn and deal creatively with relevant knowledge within design thinking-based problem solving (Lindberg et al., 2010). The two diamonds are a simplified visual illustration of the design thinking process. The creative process is iterative. Each diamond is further segmented into two distinct phases - Discover and Define for the problem space, and Develop and Delivery for the solution space. Discovering refers to divergently looking into the problem in order to notice new things and gather insights. Defining means making sense of all the insights and possibilities. The output of these first two phases is an elaborate creative brief that embodies the design challenge. It is arrived at through asking questions such as, what matters most, 


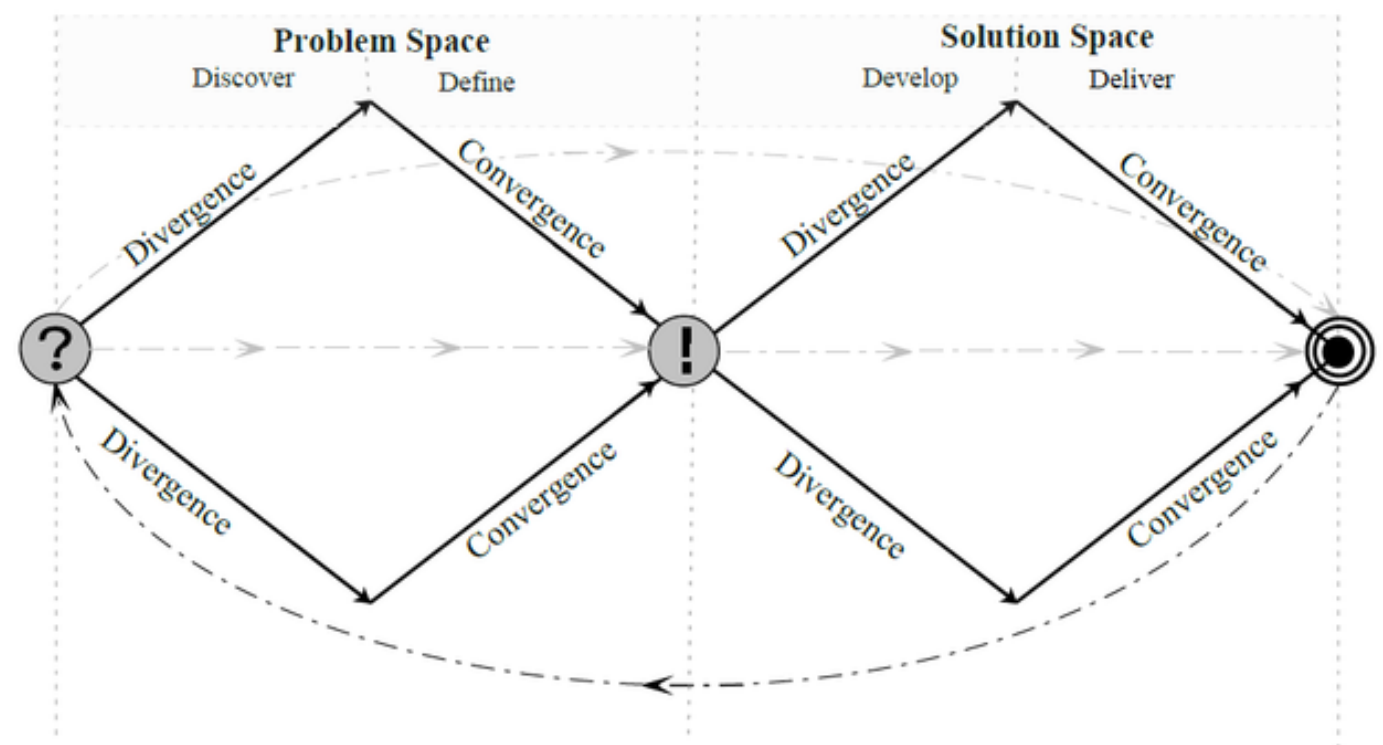

which should we act on first, what is feasible? During the Develop phase, solutions or concepts are created, prototyped, tested and iterated. Ideas are refined through trial and error. Delivery is the last phase where the design challenge is finalised and the solution launched. Figure 1 shows the double diamond model.

The double loop model adopted by IBM is a continuous cycle of observing, reflecting, and making (IBM, 2019). It resembles an infinity mathematical symbol and can also be regarded as round edged double diamond. The loop model helps design teams to understand the present and envision the future. During the observe stage, design teams immerse themselves in the real world in order to understand the problem. When reflecting, the teams come together and look within in order to interpret their findings. This represents a typical convergence. A concrete form is attached to abstract ideas during the make stage. Understanding real world problems require design thinkers to know the users, understand the context, uncover needs, and listen for feedback. This is an empathy process which require one to ask open ended questions, hear people's stories, hopes, fears, and motivating factors. Getting feedback calls for testing ideas, assumptions, and prototypes by putting them in users' hands. In order to avoid receiving misleading feedback, observers should be neutral, faithful and good listeners.

During reflection, the team synthesizes discoveries from the real-world problem, shares insights, stay aligned to the original mission. Team perspectives are often diverse and individuals should have empathy to understand each other, be flexible to respond to change, and have integrity to stay true to the team's values. Reflection should uncover new insights, thus taking a leap in clarity, reframing the team's point of view, and changing convictions about what is important. Decisions on next moves should be done together with understanding.

Creativity is born through trials, failures and retrials until something wow comes out. The make stage of the loop model coincides with the "fail early, fail often" principle of design thinking. The earlier the team makes, the faster they learn. More pain and resource waste are incurred when teams delay making. Teams must be conscious of working together in bringing ideas to life. Better communication of ideas is achieved through visuals and building prototypes to test hypotheses. Figure 2 illustrates the double loop design thinking model. 


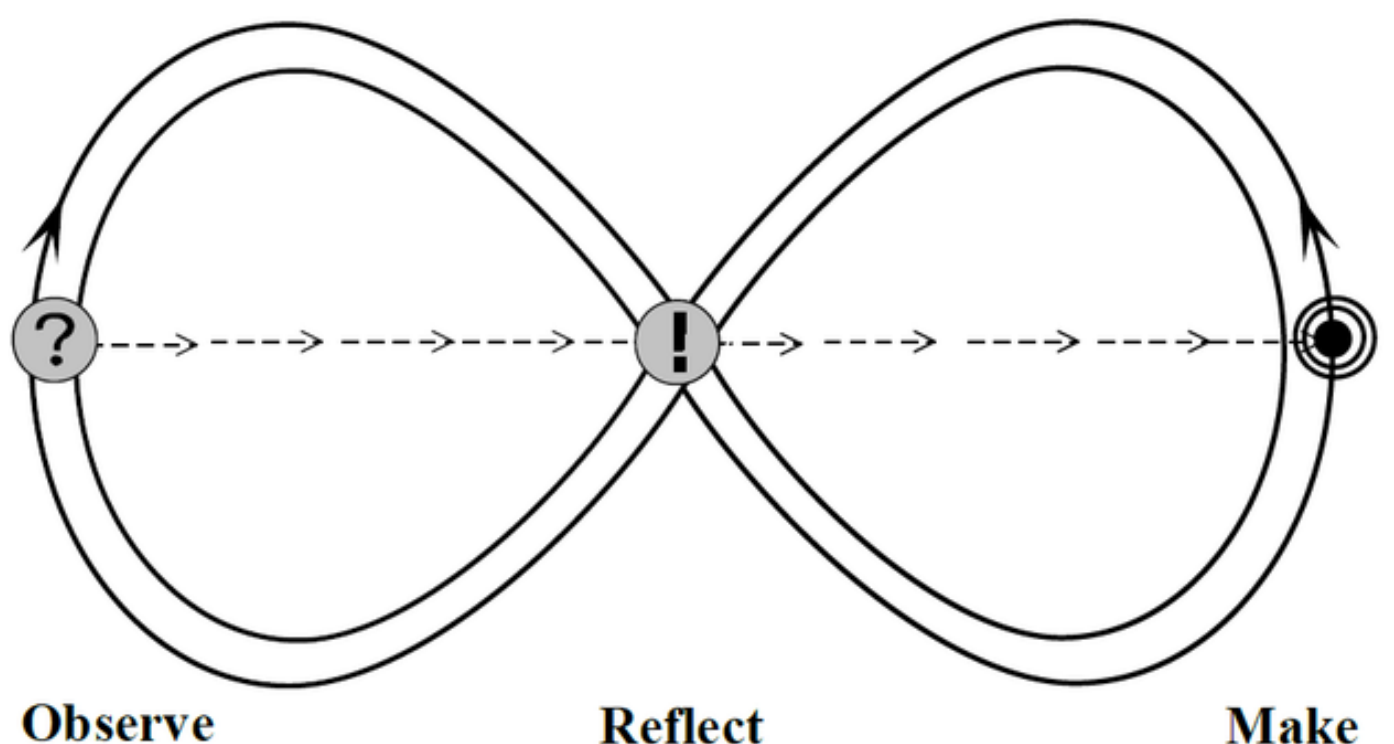

Design thinking process models tend to struggle to find the balance between flexibility and sequentiality. Brown (2008), for instance, distinguishes the general phases "inspiration", "ideation", and "implementation", and groups and orders for each phase the questions to ask or the actions to do. A didactic process model for design thinking education was formalized and adopted at the Hasso Plattner Institute (HPI) of Design at Stanford (Lindberg et al., 2010). It distinguishes the phases "understand", "observe", "synthesis/point of view", "ideate", "prototype', and "test". Figure 3 shows the didactic design thinking model, where the phases are put in a sequential order, but linearity is avoided through iterative links connecting all phases with each other.

The Hasso-Plattner Institute of Design at Stanford (i.e., d.school) proposed the five-stage design thinking model as illustrated in Figure 4. The five stages of design thinking, according to the d.school, are as follows: Empathize, Define (the problem), Ideate, Prototype, and Test. Without the feedback loops, Stanford University's design thinking process appears to describe a waterfall process but the model is iterative. The five stages of the design thinking process are described as follows (Dam \& Siang, 2019; Plattner, 2010):

Figure 3. Didactic design thinking process model.

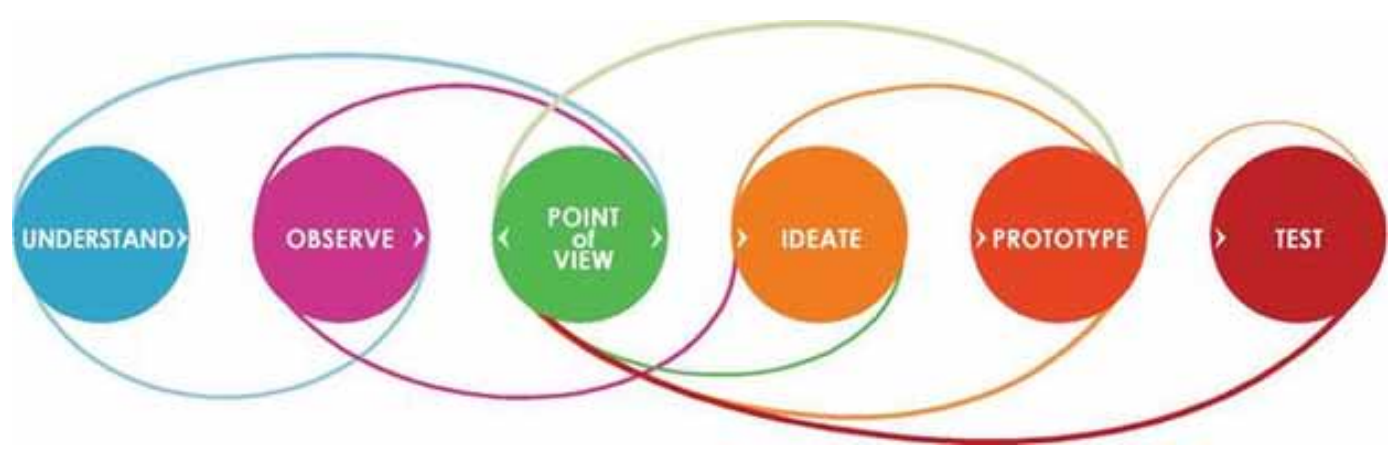


Figure 4. Five (5) stage design thinking process

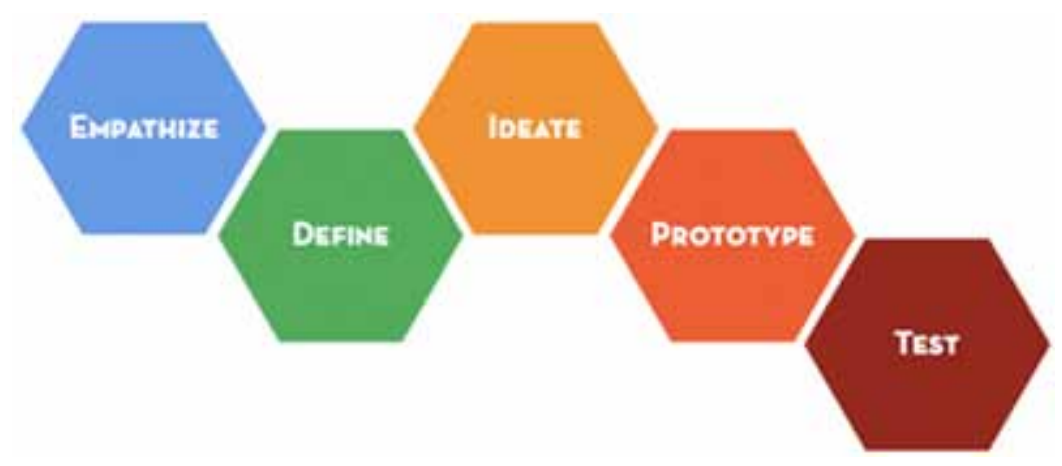

- Empathize: Seeks to fully understand the experience of the user for whom the solution is being designed. This is executed through observation, interaction, and immersing oneself in the user's experiences.

- Define: The design team synthesize the findings to form a user point of view that they will address with their design.

- Ideate: The team explores a wide variety of possible solutions through generating a large pool of ideas. There are many ways to generate ideas, such as: brainstorming, mash-up, e-storming, role play, storyboard, idea wall, sketching, quick mockup, and others.

- Prototype: Ideas are transformed into a physical form so that team members can experience and interact with them, helping them to learn and develop more empathy. The design team can produce a number of inexpensive, scaled down versions of the design solutions or specific features found in the design, so they can investigate the problem solutions generated in the previous stage. The main design team may exchange their prototype(s) by other departments, or a small group of people outside the design team. This stage is experimental and aims to identify the best possible solution for each of the problems identified during the first three stages.

- Test: Best solutions refined during prototyping are rigorously tested on real end users. The team uses observations and feedback to refine prototypes, learn more about the user, and refine the original point of view.

Knowledge processed in design thinking has to be neither representative nor entirely rationalized, rather it serves to obtain an exemplary but multi-perspective understanding in order to creatively transform it to a solution for the ambiguity of wicked problems. Three characters of design thinking workflows are: Exploring the problem space, Exploring the solution space, and Iterative alignment of both space (Lindberg et al., 2010).

\section{Industry 4.0 Innovation Challenges}

Industry 4.0 innovations are evolutionary. The modern trend is about using internet to connect intelligent machines, systems, processes, products, customers and consumers to form a sophisticated network, thus turning the real world into the connected world (Kagermann, 2015). Industry 4.0 innovation expectations are all encompassing, covering business model innovation, product, and service innovation. Specific drivers of Industry 4.0 innovations are the digitization, integration, and interconnection of products, services, value chains, and business models. Traditional structures that sustain innovation in organisations include research and development (R\&D), engineering, manufacturing and other capabilities (Jucevičius \& Galbuogienè, 2014; Rezk et al., 2015).

Top challenges that businesses are facing in Industry 4.0 are: 
- Data challenge: Industry 4.0 is data-driven. Data poses various challenges and demands new methodologies for storing, processing, visualization, and management.

- Data exchange with partners: Inter-departmental data exchange within organizations and integration help to ensure the availability of data for other processes in time.

- Training and skills development: Fast changing technology in Industry 4.0 often requires new skills that match new techniques, and enterprise facilities.

- Process flexibility: Short life cycles and high-level customization require a great deal of flexibility (Hofmann \& Bick, 2015; Hofreiter \& Huemer, 2010; Zhang, Huang, Qu, \& Sun, 2013). Standardization and synchronization are needed at inter-departmental level, and across the value chains in order to bring flexibility in an effective manner.

- Security: The proliferation of smart devices in the connected world brings a great risk from cyber security perspective. Interconnected gadgets also need constant monitoring and control (Khan \& Turowski, 2016).

Innovation is a core concept of Industry 4.0 in order to guarantee competitive advantages for organizations (Anderson, Potočnik, \& Zhou, 2014; Palazzeschi, Bucci, \& Di Fabio, 2018). It is also necessary not only to implement technological systems, but above all to develop innovative work behaviours, i.e., psychological innovation (Hammond, Neff, Farr, Schwall, \& Zhao, 2011; Lukes \& Stephan, 2017; Felin, Foss, \& Ployhart, 2015). Innovation at enterprise level is motivated by cost reduction, improved agility and short time-to-market. These can be achieved through collaboration across the boundaries of digitized value chains, and harnessing the power of data, real-time insights, and creation of new revenue streams.

\section{Hands-On Learning of Design Thinking}

Student collaboration issues in problem- and project-based pedagogies culminate in what we largely see today as "inquiry-based learning". Including project-, hands-on, inquiry-based, and problem-based learning, active and experiential learning, capstone projects, and interdisciplinary group work is "constructivist" education which is characterized by student collaboration at the core of its activities (Christopher Monson \& Novak, 2012). Hands-on approach is a method of instruction where students are guided to gain knowledge by experience (Ekwueme, Ekon, \& Ezenwa-Nebife, 2015). How design and design thinking should be taught or used has been an issue of importance in different professional fields (Li et al, 2019). In teaching and learning design thinking, learners get to know users and define user demands through stages, so as to trigger learners' creativity and inspiration and motivate them to quickly present creative ideas with a prototype. Then, the ideas are improved through testing (Tu, Liu, $\& \mathrm{Wu}, 2018)$. Design thinking require creative thinking teaching approach as opposed to traditional teaching. Traditional teaching methods, as shown in Table 1, mainly comprise of the teacher as the fountain of knowledge, tasked with spreading the knowledge among leaners in a conventional classroom setup. The main purpose of creative thinking teaching is to trigger and enhance students' creativity (Tu, Liu, \& Wu, 2018). Traditional methods are becoming obsolete. Global threats such as Covid-19 worsen the situation. Learner behavior and needs are also changing, with more emphasis towards hands-on and continuous professional development for those already on the job.

Companies like IDEO and Luma Institute have advocated and marketed design thinking as a strategy for identifying opportunities to improve the human experience (Renard, 2014). IDEO created the classic Design Thinking for Educators Toolkits and workbook (IDEO, 2012).

\section{METHODOLOGY}

The research used a six-step design thinking model which was formalized at the Hasso Plattner Institute (HPI) of Design at Stanford (Plattner \& Meinel, 2009). The six-step method is also illustrated in Figure 3. A design thinking problem was presented to a team of four people, led by two facilitators 
Table 1. Traditional teaching versus creative thinking teaching (Tu, Liu, \& Wu, 2018)

\begin{tabular}{|c|c|c|}
\hline Item & Traditional Teaching & Creative Thinking Teaching \\
\hline Teaching philosophy & $\begin{array}{l}\text { Teachers are expected to lead students } \\
\text { to become familiar with textbooks }\end{array}$ & Focus on the training of creativity \\
\hline Teaching objective & $\begin{array}{l}\text { Realize the objectives set in the } \\
\text { textbooks }\end{array}$ & $\begin{array}{l}\text { Equip students with the ability of } \\
\text { creative thinking }\end{array}$ \\
\hline Teaching mode & An unchanging model & Creative thinking \\
\hline Teaching approach & Instruction plays a dominant role & $\begin{array}{l}\text { Adopt creative thinking strategies; } \\
\text { diverse and flexible }\end{array}$ \\
\hline Role of teacher and student & One-way; dominance by teachers & $\begin{array}{l}\text { Inspirer and helper; focus on } \\
\text { teacher-student interaction }\end{array}$ \\
\hline Teaching resources & Textbooks & Diverse \\
\hline Teaching material and tool & $\begin{array}{l}\text { Textbooks, blackboards and } \\
\text { chopsticks }\end{array}$ & Diversified teaching materials \\
\hline Teaching evaluation & $\begin{array}{l}\text { Written exam-based evaluation and } \\
\text { standard answers }\end{array}$ & $\begin{array}{l}\text { Diversified evaluations and } \\
\text { flexible answers }\end{array}$ \\
\hline
\end{tabular}

who are experts in design thinking methodology. Figure 5 shows the design team at the workspace. The participants were enrolled on voluntary basis and each team was assembled anonymously through picking number cards for pairing members.

\section{Understanding}

The design thinking problem at hand was that of skilled craft businesses and associated organisations (chambers of skilled crafts and national confederations of skilled crafts) who were undergoing a massive change due to new technologies and digitalization in general. The broad problem was supplied by the industry representative, after they consulted with the concerned industry. Skilled craft businesses play a major role in the national economic body and affects numerous businesses. Staff

Figure 5. The design team in the six-step design thinking model

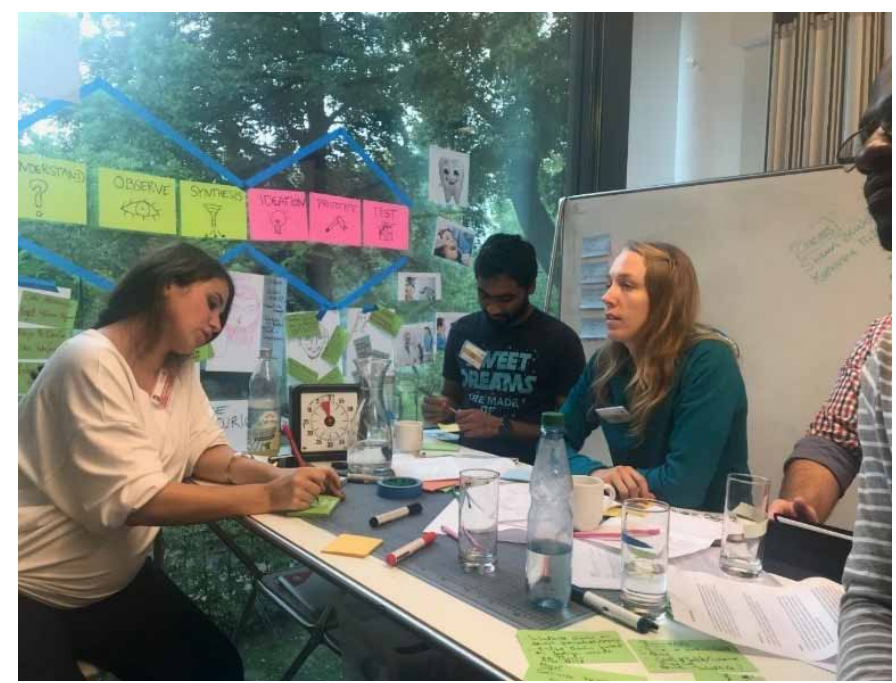




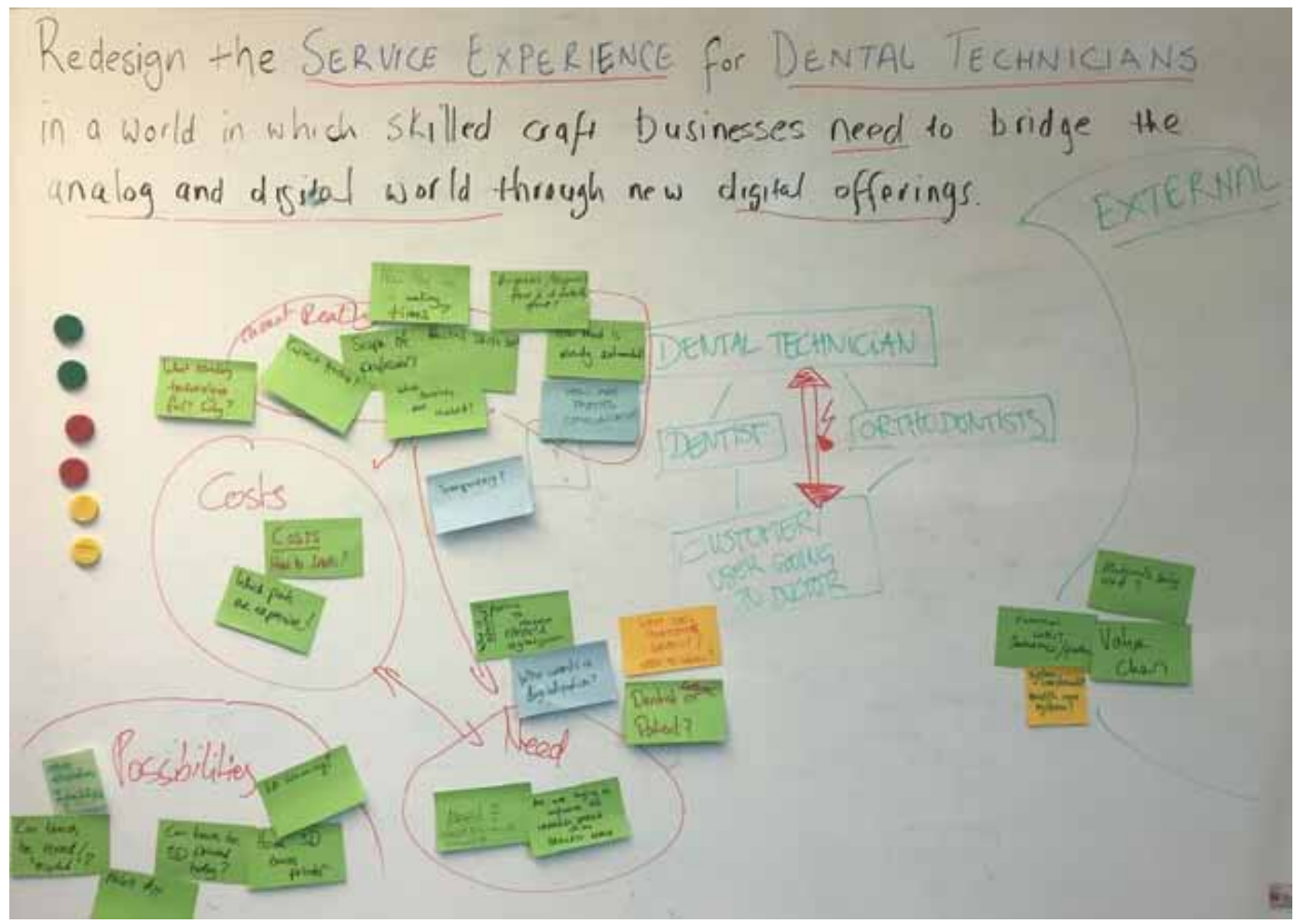

complement in such businesses range between 4-5 employees. Examples of the skilled craft businesses are bakeries, dentists and dental technicians (DT), tradesmen, optometrists, etc. New technologies are bringing significant disruptions to these businesses. The team zeroed in on dental practitioners and carried out an initial brainstorming session in seeking to gain insight to the problem as well as defining the actual problem faced by dental technicians. Figure 6 shows the design challenge and initial brainstorming.

The design team held an interview with the project partner and found out that the process of dental technician-patient could be described in the following manner:

- Dentist scans the patient's mouth

- Sends data to dentist as computer-aided design (CAD)

- DT uses 3D printing, milling and other tools to create an implant

- Design gets improved, milling and spraying

- Patient decides on the blend/material

- DT applies blend/material

\section{Observe}

During the observe phase, the team sought to gain empathy with the end users. The team did a preliminary research about the Dental Technicians industry in order to identify the industry ecosystem. All players in the DT ecosystems, excluding upper stream players, were to be interviewed in order to understand the user's journey: 
- Dental Technician

- Dentist

- Dentist Patients

- Patient who did not take a treatment for cost reasons

- Students

Interviewees were informed about the purpose of the study before participating in the interview. The questions - who, what, where, and how were used to capture user journey experiences during the interviews. Some of the findings from the interviews were as follows:

- There is bad communication between dental technicians and dentists.

- Dental technicians have the freedom to choose the preferred dentists to work with, and sometimes they choose to terminate working together when communication is too bad or in case of a bad feeling.

- Dental implants' costs range from low to very high, depending on material used.

- Dental technicians either receive patients at their practice laboratories or go to the dentists to communicate with the patients.

- Dental technicians explain matters to the patients together with the dentists, mostly using the model of the teeth.

- Patients discuss color and shape with dental technicians.

- Dental technicians mainly work with digitalization, using automatic milling machines.

Figure 7 shows the sticker notes during the interview unpacking session. Key phrases used are "we met", "we were amazed to realize, i.e., quotes and stories", and "tensions, surprises \& contradictions".

\section{Synthesis}

The design team sought to form a user point of view (POV) that addresses the design challenge. Phrases used to inform the POV are "I wonder if that means ..." and "it would be game changing to ..." Two insights were deduced during the synthesis phase: (1) a scenario of a patient who had a secure experience through a combination of dentist and dental technician working together transparently, with a likely game changing experience if the sense of transparency and trust is ensured to all patients, (2) a case of a passionate dental technician who valued staying up to date with digital technology, but barely finds time in his busy schedule. It would be game changing to support him to stay up-todate with current trends and include learning in his daily workflow. Figures 8 and 9 illustrate the synthesis process.

\section{Ideation}

The team explored a wide variety of possible solutions through generating a large pool of ideas. Figure 10 shows the star-fish brainstorming session. Various ideas that were muted are the crowd sourcing platform (ensures visibility \& trust), physical awareness and contact (mobile shop), social media, digital technology platform, and many others (Figure 11).

\section{Prototype}

Ideas were refined and transformed into a physical form to enable interaction with team members, helping them to learn and develop more empathy. A DenTech Cloud platform was prototyped and various stages of user interaction were printed on paper. The prototype was taken to random users for experimentation. Figure 12 shows the DenTech Cloud prototype homepage. The team captured feedback and unpacked the findings by categorizing feedback into the negatives (-), positives (+), 


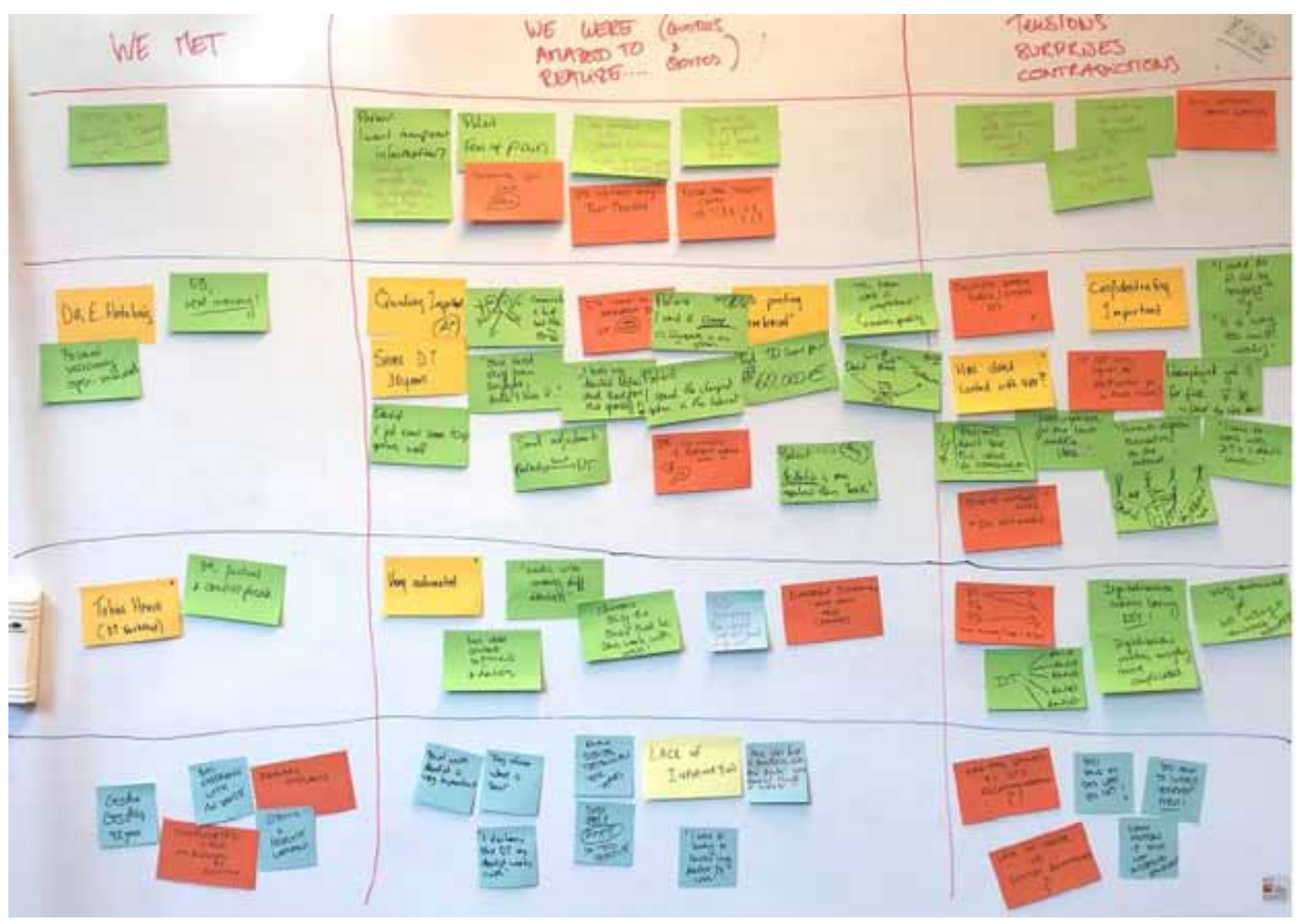

question marks (?), and insights quadrants. This helped in further refinement of the preliminary solution. Figure 13 summarizes the user feedback.

Feedback on the first prototype, although the concept was welcome, was largely negative. Users were uncomfortable with the idea of a whole new app, rather than incorporating it into existing search products, such as google search, hence making it much easier to use. Others felt that there are already many apps. The patient experience is mainly such that they look for a dentist first before they are referred to a dental technician.

Changes were made to the prototype as follows:

- $\quad$ Changed the app interface to a web-based service.

- Shifted focus from a complete patient experience to second opinion seekers only.

- The interface also informed the users of the overall network to help understand the involvement of the DTs.

After conducting another user interview and also presenting the prototype to other teams, the second prototype was refined. The team refocused to consider a different user experience. The major functions of the redefined solution were: (1) explaining the different jobs of the dentist and dental technician, (2) helping the user to find the best team of dentist-dental technician. Figure 14 shows the DenTech News concept as the final design solution fit for the design challenge. 
Figure 8. Insights

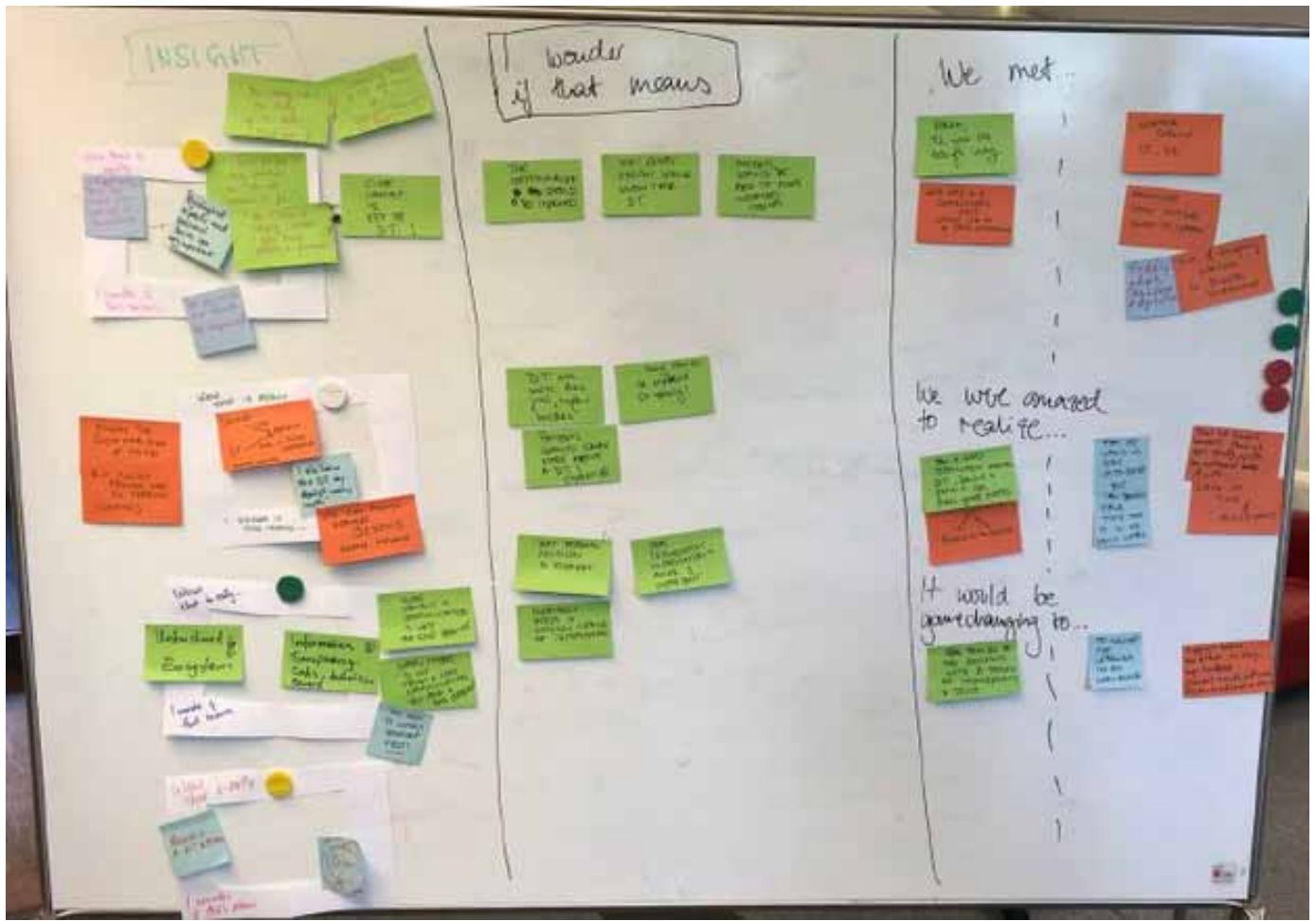

Figure 9. Game changers

\section{(1)}

We ret fieda. 2

92 yeer obl tay bily

ise val a complisted inglat

cose that ia to a bod enponence

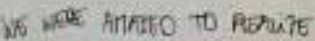

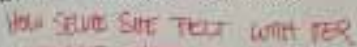

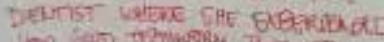

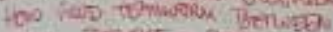

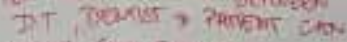

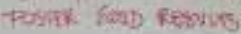

It Goud 36 conteothacang

to Thense kid Thr

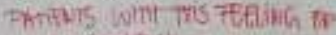

mansmeach + Tenst

\section{(2) +3}

WE TET WRIER, 52 year dIA

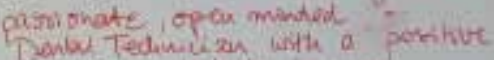

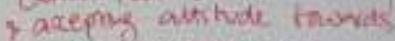
Bricithe TECHoto GY

WE WRRE MYATED TD REAUEE

That he wanks! That ha troglet

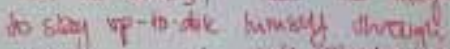
bat an I sed shidy os

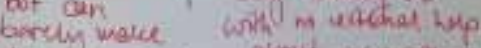

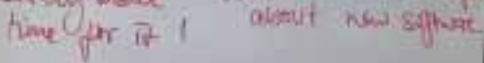

IT WruL BE Gmecimagiva TD inaluse! To secertl him चसक , कh he etfor,

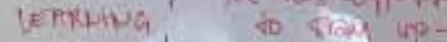
a INS initl to-date

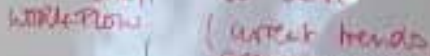
somate, wait. 


\section{Ideas - Brainstorming (star-fish)}

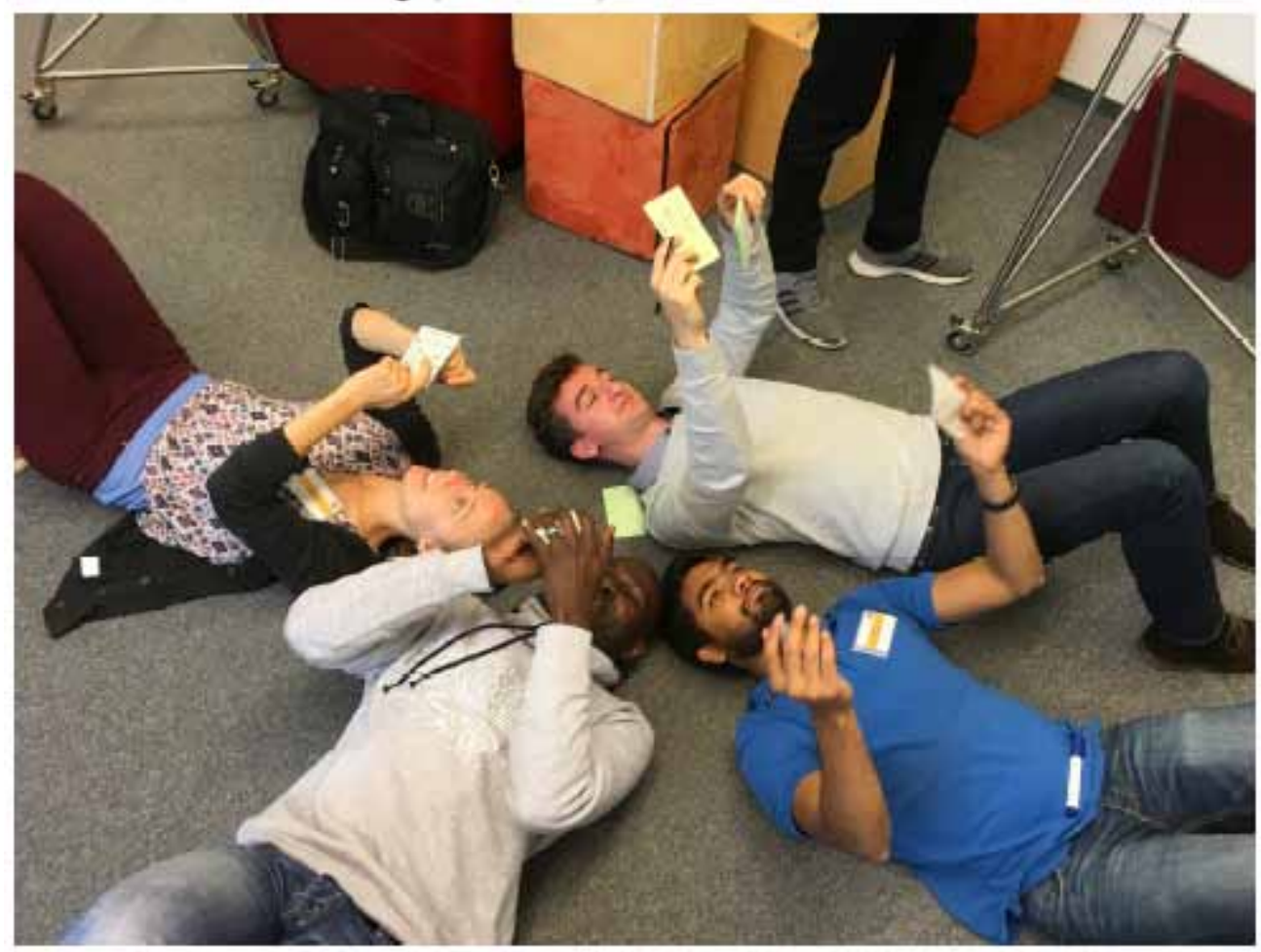

\section{Test}

The refined solution was presented to real users in the form of a role play. Although this stem forms last stage design thinking model used, the whole process is iterative. Figure 15 shows the snapshot taken whilst the team was at the role play testing booth.

\section{CONCLUSION}

The disruptive nature of Industry 4.0 significantly impacts on companies, how customers are engaged, how technologies are employed, and the value creation is processed. The article reviewed literature on different design thinking methodologies and critiqued the shortcomings of these methods. New design methods that match with industry trends prove to be gaining more momentum. The central point in modern day design solutions is the customer and the overall desire for quick time-to-market. Design thinking methodology guides companies to discover the key insights and define the correct courses of action in new innovative products and services development. The method follows a rigorous, objective, and iterative process that significantly shortens the project life cycles, whilst maintaining customer centricity. Skilled craft businesses and associated organisations (such as chambers of skilled crafts and national confederations of skilled crafts) presented their broad problem to teams of design thinkers. New technologies and digitalization in general comes as a major threat to these skilled craft businesses. This is typical of situations experienced by many business sectors in the Industry 4.0 era. Design thinking holds great potential to solve the innovation challenge at hand. Most of the technologies being adopted under the umbrella Industry 4.0 era have reached maturity but defining 
International Journal of Innovative Teaching and Learning in Higher Education

Volume 2 •Issue 1 • January-March 2021

Figure 11. Ideation board

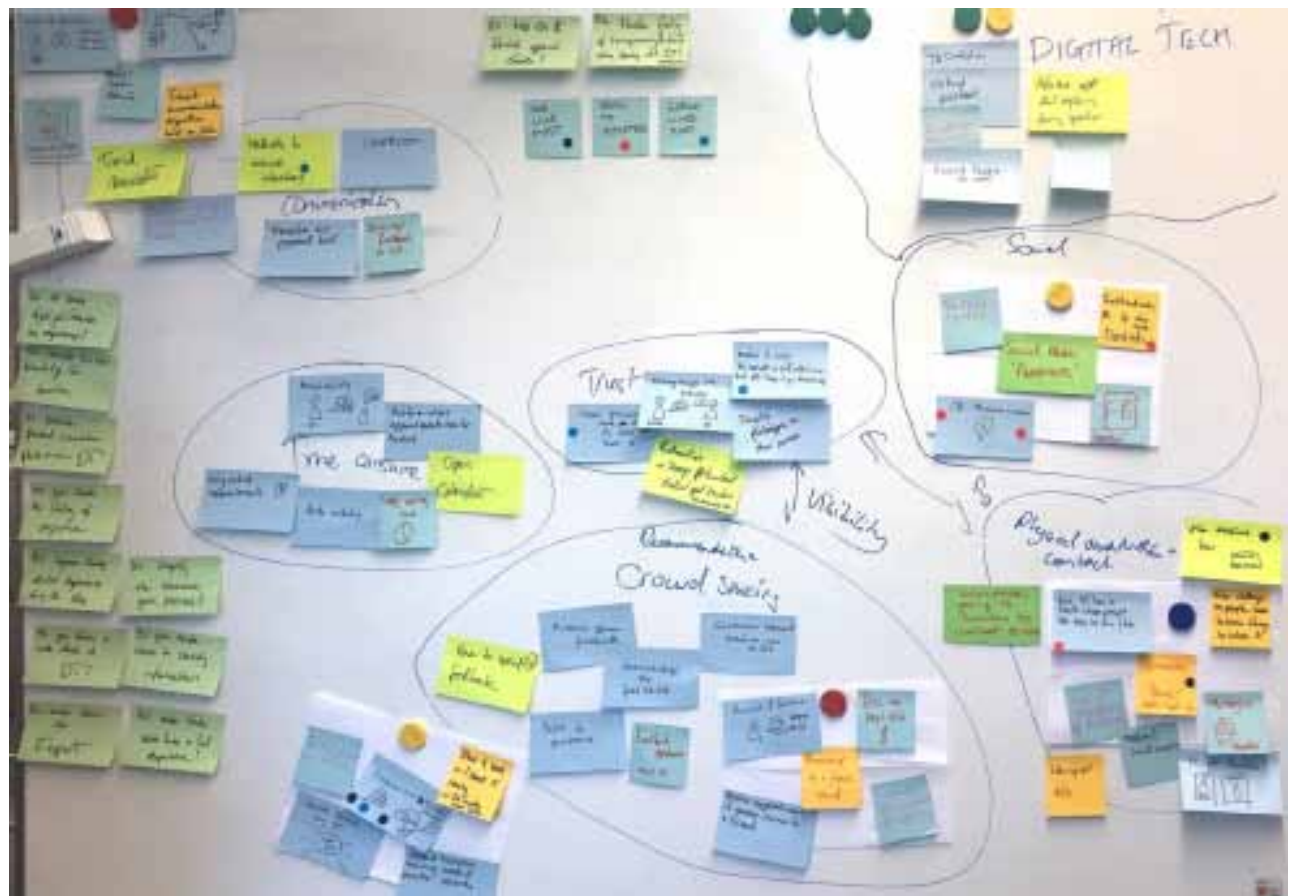

Figure 12. DenTech Cloud interface

\begin{tabular}{|c|c|c|}
\hline W DenTech Cloud | Home & ins pain & Thomas Stuart \\
\hline \multicolumn{3}{|l|}{ Seach Pertal... foy zie. MoldMsster 3000} \\
\hline Open Questions & Educate & Announcements \\
\hline 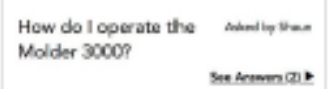 & (6) agkint & \multirow{2}{*}{ Srutasin $\mathrm{V} 2$ nom molable! } \\
\hline 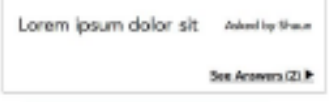 & REI3 & \\
\hline Ask Ouestion & \multirow[b]{2}{*}{ Seminars } & \multirow[b]{2}{*}{ Publications } \\
\hline Software Trials & & \\
\hline 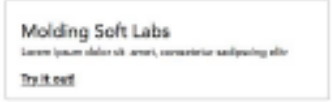 & I. Seminar about & 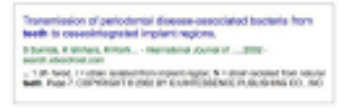 \\
\hline Soes Mare & Soes More & Soes Mare \\
\hline
\end{tabular}


Figure 13. User feedback

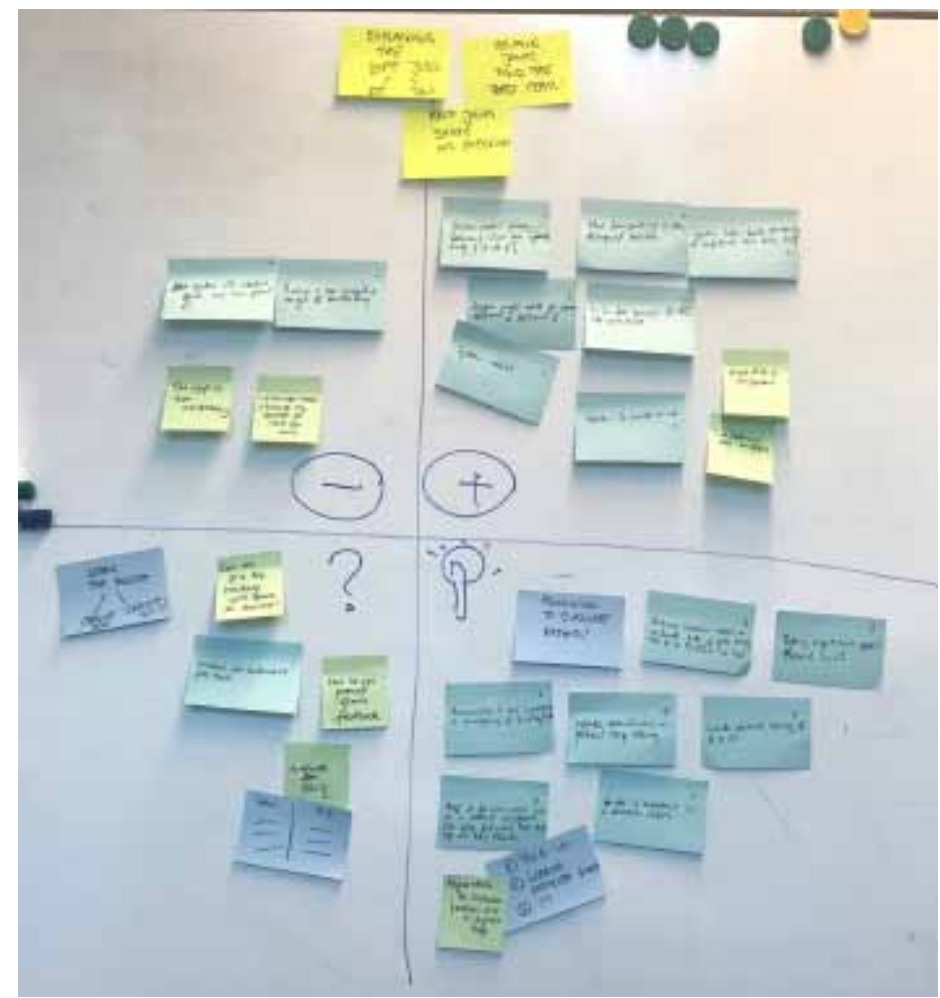

Figure 14. DenTech News cloud platform

W DenTech News Now - Ask - Seminars - Podeasts - Publications - Submit Link

1. A Michigan - Sales Tax Exemption Revoked - Labs Qualify for Industrial Processing Exemption (toddmschnednrimm

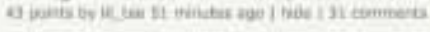

2. A NBC Announces Changes to Practical Examinations (mutimesi,com)

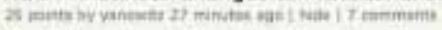

3. * Deutsche Zahnarzte in der Hurrikan-Zone (godetervine:arg)

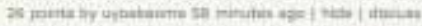

4. - Exceptionally Preserved Ancient Ships Discovered in the Black Sea temithsanianmang comi

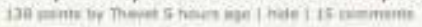

5. A Face of Defense: Dental Hygienist Continues to Serve Others (wesindanney.com)

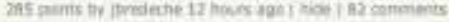

6. . Show HN: Momentum - work with lists to structure your thoughts and projects (mamentumatirth)

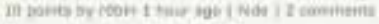

7. A Procedure for Dental Crowns (nacket-lang,org)

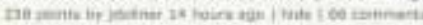

B. + Michigan - Sales Tax Exemption Revoked - Labs Qualify for Industrial Processing Exemption staddwsaneideccam)

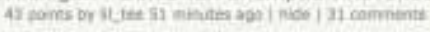

9. NEC Announces Changes to Practical Examinations (nytimasc cam)

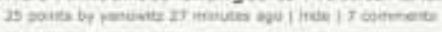

10. . Deutsche Zahnärzte in der Hurrikan-Zone (godotengine arg)

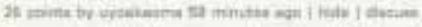

11. Exceptionally Preserved Ancient Ships Discovered in the Black Sea (amithsoninnmag,cam)

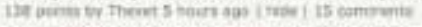

12. Face of Defense: Dental Hygienist Continues to Serve Others (wemcinneycom)

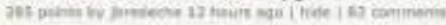

13. Show HN: Momentum - work with lists to structure your thoughts and projects (momentum.earth)

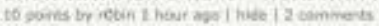




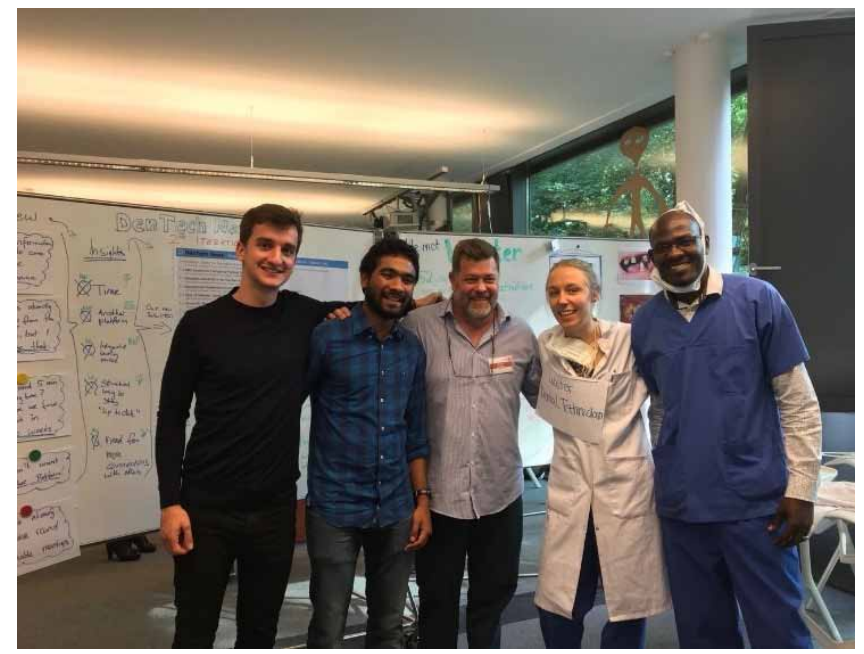

the user experience and proffering a design solution that is user centric remains a unique experience that cannot be generalised. Cultural issues and many other individualistic traits are deeply embedded in how users interact with the design solutions. The method followed in the article captures these factors throughout all the iterative stages of design thinking process.

The education sector as a crucial conduit for supplying skilled workforce needs to adapt to the fast paced changes and industry expectations in the design landscape. Rapid adoption of design thinking pedagogies across different education levels is a promising development. Drastically different from the traditional lecture-based methods, design thinking is best taught through creative thinking and hands-on models. This helps: (a) develop students' abilities to solve real-world, ill-defined problems; (b) provide opportunities for the development of concrete/iconic modes of cognition; and (c) develop nonverbal thought and communication. Hands-on learning of design thinking should be done through industry partners engagement, and executed in workspaces that promote free expression of oneself, critiques, sketching, modeling, or prototyping, and iteration.

The hands-on learning model is a vehicle for developing design thinking capacity in students. This promotes field work for users' needs inquiry. The learners and experienced trainers then use well equipped, reconfigurable working spaces or studios to quickly mock up their ideas. Iterative testing and refinement leads the teams to real world solutions that answer the users' needs. The working space aids the critical parts of the design thinking process: reflection, sketching, and modeling as non-verbal modes of cognition and iteration. Effective idea development among design thinking teams is promoted through critiques, peer feedback, and collaborative decision-making.

Role-playing helped build confidence, develop listening skills, and creative problem among the participants. By engaging in role-play activities, participants gain opportunities to view situations from multiple perspectives, in the spirit of constructivist learning theories. Design thinking learning experiences demonstrated in this paper show that role-play learning activities have the capacity to address emotional as well as cognitive dimensions of adult learning. High quality learning and teaching needs to include activities other than lectures and PowerPoint presentations in order to create a learning environment that ignites inquiry and motivation.

Despite the successes as discussed above, the activities in the six-step design thinking model were done in a limited timeframe of two weeks. Other challenges include the costs incurred during the study. Mimicking real-life scenarios require more resources, which are not always available in teaching and learning environments. Nevertheless, this pilot case study points a promising direction 
for future investigation of the use of hands-on learning of design thinking to tackle challenges in Industry 4.0 era. 


\section{REFERENCES}

Anderson, N., Potočnik, K., \& Zhou, J. (2014). Innovation and creativity in organizations: A state-of-thescience review, prospective commentary, and guiding framework. Journal of Management, 40(5), 1297-1333. doi:10.1177/0149206314527128

Baena, F., Guarin, A., Mora, J., Sauza, J., \& Retat, S. (2017). Learning factory: The path to Industry 4.0. Procedia Manufacturing, 9, 73-80. doi:10.1016/j.promfg.2017.04.022

Brown, T. (2008). Design thinking. Harvard Business Review, 86(6), 84-92. PMID:18605031

Chesson, D. (2017). Design thinker profile: Creating and validating a scale for measuring design thinking capabilities. http://aura.antioch.edu/cgi/viewcontent.cgi? article $=1398 \&$ context=etds

Dam, R., \& Siang, T. (2019). 5 Stages in the design thinking process. https://www.interaction-design.org/ literature/article/5-stages-in-the-design-thinking-process

Dunne, D., \& Martin, R. (2006). Design thinking and how it will change management education: An interview and discussion. Academy of Management Learning \& Education, 5(4), 512-523. doi:10.5465/amle.2006.23473212

Ekwueme, C. O., Ekon, E. E., \& Ezenwa-Nebife, D. C. (2015). The impact of hands-on-approach on student academic performance in basic science and mathematics. Higher Education Studies, 5(6), 47-51.

Felin, T., Foss, N. J., \& Ployhart, R. E. (2015). The microfoundations movement in strategy and organization theory. The Academy of Management Annals, 9(1), 575-632. doi:10.5465/19416520.2015.1007651

Gwangwava, N., Mpofu, K., \& Mhlanga, S. (2016). Big data and data modelling for manufacturing information systems. In Big Data: Concepts, Methodologies, Tools, and Applications (pp. 116-138). IGI Global. doi:10.4018/978-1-4666-9840-6.ch007

Hammond, M. M., Neff, N. L., Farr, J. L., Schwall, A. R., \& Zhao, X. (2011). Predictors of individual-level innovation at work: A meta-analysis. Psychology of Aesthetics, Creativity, and the Arts, 5(1), 90-105. doi:10.1037/ a0018556

Hassi, L., \& Laakso, M. (2011, October). Conceptions of design thinking in the design and management discourses. In Proceedings of IASDR2011, the 4th world conference on design research, Delft (pp. 1-10). Academic Press.

Hofmann, J., \& Bick, P. D. W. (2015). Are variant producers the pioneers. ROI Dialog, 43, 6-7.

Hofreiter, B., \& Huemer, C. (2010). Flexible workflow management in service-oriented environments. In AgentBased Service-Oriented Computing (pp. 81-111). Springer. doi:10.1007/978-1-84996-041-0_4

IBM. (2019). The framework: Design thinking re-envisioned for the modern enterprise. https://www.ibm.com/ design/thinking/page/framework/loop

IDEO. (2012). Design thinking for educators' toolkit. http://designthinkingforeducators.com

Jucevičius, R., \& Galbuogienè, A. (2014). Smart specialization: Towards the potential application of the concept for the local development. Procedia: Social and Behavioral Sciences, 156, 141-145. doi:10.1016/j. sbspro.2014.11.136

Kagermann, H. (2015). Change through digitization-Value creation in the age of Industry 4.0. In Management of Permanent Change. Springer. doi:10.1007/978-3-658-05014-6_2

Kagermann, H., Helbig, J., Hellinger, A., \& Wahlster, W. (2013). Recommendations for implementing the strategic initiative INDUSTRIE 4.0: Final report of the Industry 4.0 Working Group. https://www.din.de/blob/76902/ e8cac883f42bf28536e7e8165993f1fd/recommendations-for-implementing-industry-4-0-data.pdf

Khan, A., \& Turowski, K. (2016, April). A perspective on Industry 4.0: From challenges to opportunities in production systems. In International Conference on Internet of Things and Big Data (pp. 441-448). SCITEPRESS. doi: $10.5220 / 0005929704410448$ 
Li, Y., Schoenfeld, A. H., Graesser, A. C., Benson, L. C., English, L. D., \& Duschl, R. A. (2019). Design and design thinking in STEM education. Journal for STEM Education Research, 2(2), 93-104. doi:10.1007/s41979019-00020-z

Lindberg, T., Gumienny, R., Jobst, B., \& Meinel, C. (2010). Is there a need for a design thinking process. Design Thinking Research Symposium, 8, 243-254.

Lukes, M., \& Stephan, U. (2017). Measuring employee innovation. International Journal of Entrepreneurial Behaviour \& Research, 23(1), 136-158. doi:10.1108/IJEBR-11-2015-0262

Mell, P., \& Grance, T. (2011). The NIST definition of cloud computing. Academic Press.

Melles, G., Anderson, N., Barrett, T., \& Thompson-Whiteside, S. (2015). Problem Finding through Design Thinking in Education. In Inquiry-Based Learning for Multidisciplinary Programs: A Conceptual and Practical Resource for Educators (pp. 191-209). Emerald Group. doi:10.1108/S2055-364120150000003027

Menon, U., \& Graham, M. (1996). Concurrent engineering: Effective deployment strategies. Production, 6(2), 165-181. doi:10.1590/S0103-65131996000200002

Monson, C. R. A., \& Novak, V. (2012). Design thinking as a method for authentic student collaboration for inquiry-based learning. In Proceedings of the 4th Annual Conference on Higher Education Pedagogy. https:// chep.teaching.vt.edu/content/dam/chep_teaching_vt_edu/2012ConferenceProceedings.pdf

Noel, L. A., \& Liub, T. L. (2017). Using design thinking to create a new education paradigm for elementary level children for higher student engagement and success. Journal of Design and Technology Education, 22(1), n1.

Owen, C. (2007). Design thinking: Notes on its nature and use. Design Research Quarterly, 2(1), 16-27.

Palazzeschi, L., Bucci, O., \& Di Fabio, A. (2018). Re-thinking innovation in organizations in the Industry 4.0 scenario: New challenges in a primary prevention perspective. Frontiers in Psychology, 9, 30. doi:10.3389/ fpsyg.2018.00030 PMID:29445349

Plattner, H., Meinel, C., \& Weinberg, U. (2009). Design thinking. Informatik Spektrum, 39(4), 310-314. doi:10.1007/s00287-016-0977-2

Posada, J., Toro, C., Barandiaran, I., Oyarzun, D., Stricker, D., de Amicis, R., Pinto, E. B., Eisert, P., Dollner, J., \& Vallarino, I. (2015). Visual computing as a key enabling technology for industrie 4.0 and industrial internet. IEEE Computer Graphics and Applications, 35(2), 26-40. doi:10.1109/MCG.2015.45 PMID:25807506

Rajkumar, R., Lee, I., Sha, L., \& Stankovic, J. (2010, June). Cyber-physical systems: The next computing revolution. In Design automation conference (pp. 731-736). IEEE.

Razzouk, R., \& Shute, V. (2012). What is design thinking and why is it important? Review of Educational Research, 82(3), 330-348. doi:10.3102/0034654312457429

Renard, H. (2014). Cultivating design thinking in students through material inquiry. International Journal on Teaching and Learning in Higher Education, 26(3), 414-424.

Rezk, M. R. A., Ibrahim, H. H., Tvaronavičienė, M., Sakr, M. M., \& Piccinetti, L. (2015). Measuring innovations in Egypt: Case of industry. Entrepreneurship and Sustainability Issues, 3(1), 47-55. doi:10.9770/jesi.2015.3.1(4)

Tu, J. C., Liu, L. X., \& Wu, K. Y. (2018). Study on the learning effectiveness of Stanford design thinking in integrated design education. Sustainability, 10(8), 2649. doi:10.3390/su10082649

Zhang, Y., Huang, G. Q., Qu, T., \& Sun, S. (2013). Real-time work-in-progress management for ubiquitous manufacturing environment. In Cloud Manufacturing (pp. 193-216). Springer. doi:10.1007/978-1-4471-4935-4_9

Norman Gwangwava is a Senior Lecturer at the Botswana International University of Science and Technology (BIUST), department of Mechanical, Energy and Industrial Engineering. He has presented and published many research papers at conferences and refereed journals. Research interests are in; Reconfigurable Manufacturing Systems (RMS), Cyber-Physical Production Systems (CPS), Collaborative Product Design and Closed Loop Life-Cycle Systems, Business Process Modeling, Analysis and Optimization, Quality Systems \& Lean Six Sigma. He holds a DTech in Industrial Engineering from Tshwane University of Technology, South Africa and a Master of Engineering in Manufacturing Systems and Operations Management from the National University of Science and Technology, Zimbabwe. He is a member of the SAIIE-ZA and ZIE-ZW. 